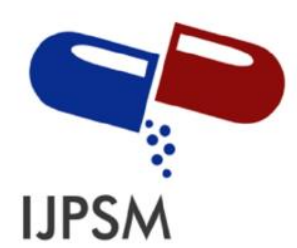

Nelvia Helsinta et al, Int. Journal of Pharmaceutical Sciences and Medicine (IJPSM),

Vol.6 Issue. 6, June- 2021, pg. 42-51

ISSN: 2519-9889

Impact Factor: 3.426

\title{
Review: Solid Dispersion of Fenofibrate Using Poly Ethylene Glycol 6000
}

\author{
Nelvia Helsinta ${ }^{1}$; Auzal Halim ${ }^{1}$; Maria Dona Octavia ${ }^{1}$; Harrizul Rivai ${ }^{2 *}$ \\ ${ }^{1}$ College of Pharmacy (STIFARM), Jl. Raya Siteba Kurao Pagang, Padang 25147, Indonesia \\ ${ }^{2}$ Faculty of Pharmacy, Andalas University, Limau Manih Campus, Padang 25163, Indonesia \\ "Email: harrizul@yahoo.co.id and harrizul@phar.unand.ac.id \\ DOI: 10.47760/ijpsm.2021.v06i06.005
}

\begin{abstract}
This review aimed to find information about the solubility of the fenofibrate solid dispersion system using PEG 6000 . Fenofibrate is an antihyperlipidemic drug that belongs to the Biopharmaceutical Classification System Class II (BCS II) with low solubility. To find information was by conducting a literature search in national and international journals in the last ten years (2010-2020) through websites, namely Google Scholar, Science Direct, NCBI, ResearchGate, and other trusted journals. Several keywords were used as follows: fenofibrate, solid dispersion, PEG 6000, and dissolution rate. The results of several research journals showed that the solid dispersion of fenofibrate using PEG 6000 made by various methods causes a reduction in particle size to increase the solubility and dissolution rate of fenofibrate. The solid dispersions system was made using several methods, namely fusion (melting), solvent evaporation, dropping, and cogrinding, which is a technique used to increase the solubility of a drug. PEG 6000 was chosen as the carrier because it has high hydrophilicity, is non-toxic, inert, economical, has a low melting point, and is dense at melting temperature to withstand crystallization. Thus it can be concluded that the manufacture of solid dispersion of fenofibrate using PEG 6000 and several methods showed the same results, namely an increase in solubility and dissolution rate.
\end{abstract}

Keywords: Fenofibrate, Solid dispersion, PEG-6000, Dissolution rate

\section{Introduction}

Solubility is a mass of solute that dissolves in a specific volume of solvent and temperature. A drug compound administered by any route must be water-soluble to produce systemic absorption and therapeutic response [1]. Solubility is one of the essential parameters so that the drug concentration can reach the systemic circulation to achieve the desired pharmacological response [2]. So it is necessary to increase the solubility and dissolution rate for poorly soluble drugs because low solubility has poor bioavailability [3]. Fenofibrate is one of the drugs belonging to class II in the BCS system (Biopharmaceutical Classification System), which is a third-generation fibric acid derivative with low solubility and high permeability [4]. Fenofibrate is a drug used to treat atherogenic dyslipidemia, which causes a substantial decrease in triglyceride-rich lipoproteins and increases in high-density lipoprotein (HDL) levels. Fenofibrate is a hyperlipidemic drug that is not soluble in water. Modifying the dissolution rate of poorly soluble drugs in water requires solid dispersions between the drug and water-soluble polymers [5]. The chemical structure of fenofibrate is shown in Figure 1. 


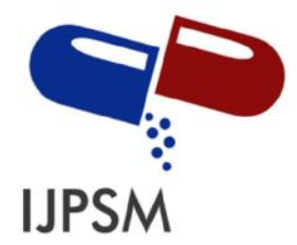

Nelvia Helsinta et al, Int. Journal of Pharmaceutical Sciences and Medicine (IJPSM), Vol.6 Issue. 6, June- 2021, pg. 42-51

ISSN: 2519-9889

Impact Factor: 3.426<smiles>CC(C)OC(=O)C(C)(C)Oc1ccc(C(=O)c2ccc(Cl)cc2)cc1</smiles>

Figure 1: Chemical structure of fenofibrate [6]

Fenofibrate is a white powder to practically white crystalline powder. Fenofibrate is almost insoluble in water, very soluble in methylene chloride, and poorly soluble in ethanol. Fenofibrate substantially modifies the distribution of low-density lipoproteins (LDL) subfraction. Recent data show that many of the effects. Another beneficial lipid modifier of fenofibrate is mediated via the peroxisome proliferator-activated receptor (PPAR). Through this mechanism, fenofibrate markedly reduces plasma triglyceride levels by increasing lipolysis and clearance of triglyceride-rich lipoproteins from plasma through activation of the enzyme lipoprotein lipase and decreased production apolipoprotein CIII. Activation of acyl coenzymes synthetase expression and subsequent stimulation of fatty acid oxidation decreased fatty acid and triglyceride synthesis. It decreased VLDL triglyceride production also contribute to the hypertriglyceridemic effect of fenofibrate [7].

\section{Data Collection}

In this review, the researchers used research sources and data search strategies used as references in writing this review article, namely by browsing literature in journals (both national and international), articles, and books through search engines available online. The way to find information was by conducting a literature search in national and international journals in the last ten years (2010-2020). Google Scholar, Science Direct, NCBI, ResearchGate, and several other journal provider sites used the main library sites.

\section{Solid Dispersion}

Solid dispersion is a solid product consisting of at least two components: a hydrophilic matrix, which can be crystalline or amorphous, and a hydrophobic drug that will be dispersed molecularly on matrix particles amorphous or crystalline, to increase the dissolution speed [8]. The study by Salman et al. (2015) [23] has shown that dispersions of ketoprofen into water-soluble polymer PVP K-30 formed amorphous ketoprofen in a solid dispersion system. All amorphous solid dispersion of ketoprofen in PVP K-30 prepared by solvent co-evaporation demonstrated a significant improvement in the dissolution rate of ketoprofen compared to pure ketoprofen. Based on research conducted on the manufacture of celery herb extract nanocrystals with different concentrations of Poloxamer 188 on the nanocrystalline characteristics of celery herb extract (Apium graveolens L.), Rosaini et al. (2021) [24] can be concluded that the optimal concentration of Poloxamer 188 has not been obtained. X-ray diffraction characterization showed a decrease in celery herb extracts' crystal intensity in all formulas compared to celery herb extracts but still showed sharp peaks. Several approaches can be taken to increase the solubility and dissolution rate, including modifying the solid properties of solid drug compounds using a solid dispersion system technique. In a solid dispersion system, the crystalline phase of the drug will be converted into an amorphous or partially amorphous phase. The amorphous phase of a solid compound is a form that is rich in energy (high energetic forms), which has a higher solubility and dissolution rate than the crystalline phase. One of the polymers used in solid dispersions is polyethylene glycol (PEG) 6000 [9]. 


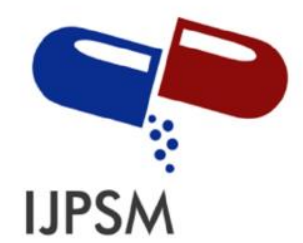

\section{Nelvia Helsinta et al, Int. Journal of Pharmaceutical Sciences and Medicine (IJPSM), Vol.6 Issue. 6, June- 2021, pg. 42-51}

In general, a solid dispersion system can be done by several methods: [9] [10]

1. Melting method

The melting method involves melting or fusing the physical preparation and the drug mixture of water-soluble carriers and directly heating to melt. The melted mixture is then rapidly solidified in an ice bath while stirring vigorously. The final solid mass is crushed and sieved.

2. Solvent method In this method, the drug and carrier are dissolved in an organic solvent and inorganic. The first step is to make a solution containing the matrix and the drug, then form a solid dispersion system.

3. Melting- solvent method This method is done by dissolving the drug in a suitable solvent, then incorporating the solution into the matrix that has melted, then evaporating it until perfect: only remaining the film layer.

4. Co-grinding method

The physical mixture of drug and carrier is mixed using a blender at a certain speed. The mixture is then fed into the steel ball chamber of the added vibration ball mill. The powder mixture is mashed. Then the samples are collected and stored at room temperature in screw-sealed glass bottles until use.

5. Spray-Drying method

The drug is dissolved in a suitable solvent, and the required amount of carrier is dissolved in water. The solution is then mixed by sonication or another practical method to produce a clear solution, then spray dried using a spray dryer.

6. Kneading technique

In this method, the carrier is absorbed with water and converted into paste. The drug is then added and kneaded for a specific time. The kneaded mixture is then dried and passed through a sieve if necessary.

7. Lyophilization technique (freeze-dry)

Performed by mixing technique in which the drug and matrix are dissolved in a solvent, then frozen to sublimate to obtain lyophilized molecular dispersion. This technique is recommended as an alternative technique for solvent evaporation.

\section{Polyethylene Glycol (PEG 6000)}

The chemical structure of polyethylene glycol is shown in Figure 2.

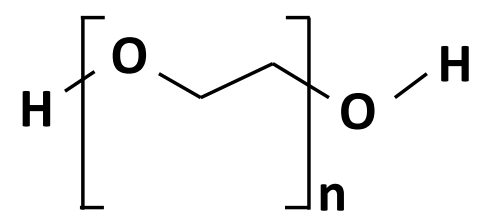

Figure 2: Chemical Structure Polyethylene Glycol 6000 [11]

Polyethylene glycol 6000 is a polycondensation product mixture of ethylene oxide and water obtained under controlled conditions. The formula is represented by $\mathrm{HOCH}_{2}\left[\mathrm{CH}_{2} \mathrm{OCH}_{2}\right] \mathrm{nCH} \mathrm{CH}_{2} \mathrm{OH}$, where $\mathrm{n}$ is between 112 and 158. PEG 6000 is a waxy flake that is solid, white in color, and a loose powder. Polyethylene glycol has a molecular weight range of 200-300000, a molecular weight of 200-600 is in liquid form, a weight of 1500 is in the form of a concentrated liquid, a molecular weight of 3000-20000 is a crystalline semisolid, and polyethylene glycol with a weight of more than 100000 is a receipt at room temperature. This polymer is easily soluble in various solvents, has a low melting point and toxicity, and 


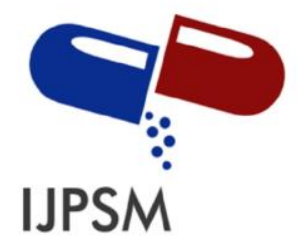

Nelvia Helsinta et al, Int. Journal of Pharmaceutical Sciences and Medicine (IJPSM), Vol.6 Issue. 6, June- 2021, pg. 42-51

exists in semi-crystalline form. Most of the PEGs used have molecular weights between 4000-20000, particularly PEG 4000 and 6000 [12].

Polyethylene glycol (PEG 6000) is one of the polymers that can form polymer complexes. On drug molecules that function as water solubility enhancers, polyethylene glycol can be used in solid dispersion methods and added to medicinal ingredients with low solubility in water. This polymer is inert, not easily hydrolyzed, and the most important thing is that it cannot be grown by fungi. The advantage of using PEG 6000 is that it can increase drug solubility, increase drug stability, increase circulation time and improve drug release profile [13].

\section{Solid Dispersion of Fenofibrate}

A comparison of solid dispersion of fenofibrate using various carriers was shown in Table 1.

Table 1: Solid dispersion of fenofibrate using various carriers

\begin{tabular}{|c|c|c|c|}
\hline Refs. & Methods & Carriers & Conclusion \\
\hline$[14]$ & $\begin{array}{c}\text { Solvent } \\
\text { Evaporation } \\
\text { method using a } \\
\text { fluid-bed coating } \\
\text { technique }\end{array}$ & $\begin{array}{l}\text { PEG-400, PEG- } \\
\text { 6000, MCC, } \\
\text { pregelatinized } \\
\text { starch, cremophore }\end{array}$ & $\begin{array}{l}\text { PEG, MCC, pregelatinized starch has increased the } \\
\text { solubility and bioavailability of fenofibrate } \\
\text { significantly }\end{array}$ \\
\hline [15] & $\begin{array}{l}\text { Physical mixture } \\
\text { and kneading } \\
\text { method }\end{array}$ & $\begin{array}{l}\text { Agar, karaya gum, } \\
\text { treated agar, } \\
\text { modified karaya } \\
\text { gum, PEG 4000, } \\
\text { and PEG } \\
6000 \\
\end{array}$ & $\begin{array}{l}\text { Solid dispersions of fenofibrate prepared by kneading } \\
\text { method with synthetic carrier PEG } 6000 \text { enhance the } \\
\text { dissolution rate. }\end{array}$ \\
\hline$[16]$ & $\begin{array}{l}\text { Fusion method and } \\
\text { solvent } \\
\text { evaporation } \\
\text { method }\end{array}$ & $\begin{array}{l}\text { PEG } 6000 \text { and } \\
\text { PVP K30 }\end{array}$ & $\begin{array}{l}\text { Solid dispersion prepared with PVP K- } 30 \text { in } 1: 4 \text { ratio } \\
\text { by solvent evaporation method was more soluble than } \\
\text { fusion. }\end{array}$ \\
\hline [17] & $\begin{array}{l}\text { Solvent } \\
\text { evaporation } \\
\text { method }\end{array}$ & $\begin{array}{l}\text { Poloxamer 188, } \\
\text { Poloxamer 407, } \\
\text { Polyethylene } \\
\text { glycol (PEG) 6000, } \\
\text { Polyvinyl } \\
\text { Pyrrolidone (PVP), } \\
\text { Hydroxypropyl } \\
\text { methylcellulose } \\
\text { (HPMC), and } \\
\text { Mannitol }\end{array}$ & $\begin{array}{l}\text { Solid dispersion prepared with Poloxamer } 188 \\
\text { showed the fastest. Full release (93.74 \%) among all } \\
\text { formulations and solid dispersions with PVP, HPMC, } \\
\text { Poloxamer } 407 \text {, PEG } 6000 \text {, Mannitol showed } 88.21 \\
\%, 88.14 \%, 82.87 \%, 76.50 \% \text {, and } 65.77 \% \text { release } \\
\text { respectively in } 1: 10 \text { ratio within } 1 \text { hour whereas pure } \\
\text { fenofibrate showed only } 23.60 \% \text { release. }\end{array}$ \\
\hline [18] & $\begin{array}{l}\text { Fusion (melting) } \\
\text { and solvent } \\
\text { evaporation } \\
\text { methods }\end{array}$ & $\begin{array}{l}\text { PEG } 6000, \\
\text { Poloxamer } 407, \\
\text { and a mixture of } \\
\text { PEG } 6000 \text { and } \\
\text { Poloxamer } 407 \\
\text { (1:1 mixture) }\end{array}$ & $\begin{array}{l}\text { Solid dispersions containing fenofibrate/Poloxamer } \\
407,1: 8 \text { showed a } 14 \text {-fold increase in dissolution } \\
\text { after } 60 \text { min (D60) and another dispersion containing } \\
\text { fenofibrate/PEG } 6000,1: 10 \text {, showed an } 8 \text {-fold rise in } \\
\text { the } 0.1 \mathrm{~N} \mathrm{HCl} \mathrm{systems.} \mathrm{The} \mathrm{dispersion} \mathrm{containing} \mathrm{six} \\
\text { parts of the PEG } 6000 \text { : Poloxamer } 407 \text { mixture (PEG } \\
4000 / \text { PEG } 6000,1: 1 \text { mixture) showed a } 12 \text {-fold } \\
\text { increase in D60 compared with pure drug. When the } \\
\text { solvent method prepared multi-carrier solid }\end{array}$ \\
\hline
\end{tabular}




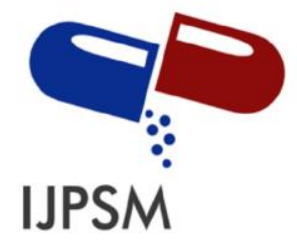

Nelvia Helsinta et al, Int. Journal of Pharmaceutical Sciences and Medicine (IJPSM), Vol.6 Issue. 6, June- 2021, pg. 42-51

\begin{tabular}{|c|c|c|c|}
\hline & & & $\begin{array}{l}\text { dispersion containing six parts of variety, the D60 } \\
\text { value was about } 2 \text {-fold that of the same dispersion } \\
\text { prepared by the melt method. The dissolution of } \\
\text { lyophilized solid dispersions further increased the } \\
\text { dissolution of fenofibrate significantly. }\end{array}$ \\
\hline [19] & $\begin{array}{l}\text { Fusion and solvent } \\
\text { evaporation }\end{array}$ & $\begin{array}{l}\text { PEG 4000, PEG } \\
6000, \text { and a } \\
\text { mixture of PEG } \\
4000 \text { and PEG } \\
6000\end{array}$ & $\begin{array}{l}\text { When multi-carrier solid dispersion containing the } \\
\text { fifth parts of the cross was prepared by the solvent } \\
\text { method, the D } 60 \text { value was about } 2 \text {-fold that of the } \\
\text { same dispersion prepared by the solvent method. The } \\
\text { dissolution of the solvent method prepare by solid } \\
\text { dispersions further increased the dissolution of } \\
\text { fenofibrate significantly. }\end{array}$ \\
\hline [20] & $\begin{array}{c}\text { Evaporation of } \\
\text { solvent }\end{array}$ & $\begin{array}{l}\text { HPMC, Poloxamer } \\
\text { 188, Poloxamer } \\
\text { 407, PEG } 6000\end{array}$ & $\begin{array}{l}\text { These formulations can increase the dissolution as } \\
\text { well as can increase the absorption rate and } \\
\text { bioavailability of fenofibrate. These formulations } \\
\text { enhance the dissolution and bioavailability of } \\
\text { fenofibrate and good formulation candidates for } \\
\text { fenofibrate in the future. }\end{array}$ \\
\hline [21] & $\begin{array}{l}\text { Solvent } \\
\text { evaporation or co- } \\
\text { grinding }\end{array}$ & $\begin{array}{l}\text { HPMC, PVP, and } \\
\text { PEG of various } \\
\text { molecular weights }\end{array}$ & $\begin{array}{l}\text { Fenofibrate was molecularly dispersed in HPMC and } \\
\text { PVP. In contrast, it was partially dissolved and } \\
\text { partially dispersed in the form of tiny crystals in } \\
\text { PEG, irrespective of the type of preparation } \\
\text { technique. Differences in the particle size could } \\
\text { explain why drug release was faster from PVP-based } \\
\text { systems prepared by solvent evaporation compared to } \\
\text { co-grinding and why the opposite was confirmed in } \\
\text { the case of PEG. For HPMC, differences in system } \\
\text { homogeneity could explain the effects of the type of } \\
\text { preparation method. Significantly, the drug } \\
\text { dissolution rate and extent could be substantially } \\
\text { increased while assuring stability during at least three } \\
\text { months of open storage. }\end{array}$ \\
\hline [22] & $\begin{array}{l}\text { Physical mixture } \\
\text { and kneading } \\
\text { method }\end{array}$ & $\begin{array}{l}\text { Agar, karaya gum, } \\
\text { treated agar, } \\
\text { modified karaya } \\
\text { gum, PEG } 4000 \\
\text { and PEG } 6000\end{array}$ & $\begin{array}{l}\text { Solid dispersions of fenofibrate prepared by kneading } \\
\text { method with synthetic carrier PEG } 6000 \text { enhance the } \\
\text { dissolution rate. }\end{array}$ \\
\hline
\end{tabular}

Fenofibrate is a lipid-lowering drug used to treat hyperlipidemia, which is not soluble in water and lower absorption in gastric fluid. To improve the solubility and oral absorption of the drug in gastric juice and enhance its dissolution rate, Vinay et al. (2012) [14] have designed and evaluated solid dispersions of fenofibrate. Solid dispersions of fenofibrate were prepared using various carriers' ratios like PEG-400, PEG6000, MCC, pregelatinized starch, cremophor (formulations from F1 to F9 and one reproducibility batch F10 were formulated). Then prepared solid dispersions were evaluated for in vitro dissolution, differential scanning calorimetry, and stability studies were conducted. Solid dispersion with PEG was developed in a different ratio. The differential scanning calorimetry demonstrated that enhanced dissolution of fenofibrate from solid dispersion might be due to a decrease in the crystallinity of fenofibrate in a carrier in solid dispersion 


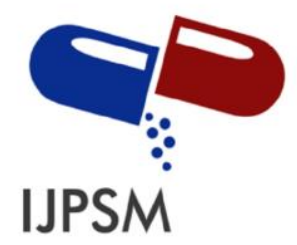

\section{Nelvia Helsinta et al, Int. Journal of Pharmaceutical Sciences and Medicine (IJPSM), Vol.6 Issue. 6, June- 2021, pg. 42-51}

preparation. PEG, MCC, pregelatinized starch have increased the solubility and bioavailability of fenofibrate significantly.

The main objective of the study by Prasanthi et al. (2019) [15] was to compare the effect of natural carriers and synthetic carriers in the dissolution of fenofibrate (BCS class II), a poorly soluble drug. Fenofibrate is an antihyperlipidemic drug that reduces both cholesterol and triglycerides in the blood. Nowadays, the formulation of poorly soluble compounds for oral delivery is the most frequent and most significant challenge to formulation scientists in the pharmaceutical industry. There are many drugs for which dissolution poses a challenge for formulating oral dosage forms leading to bioavailability problems. The solid dispersions of the drug were prepared by different methods like physical mixture and kneading method with natural and synthetic carriers like agar, karaya gum, treated agar, modified karaya gum, PEG 4000, and PEG 6000 in the ratios of 1:2 to 1:10. Resultant formulations were evaluated for solubility, assay, flow properties, FTIR, X-ray diffraction, DSC, and in vitro dissolution. Solubility of the solid dispersions was enhanced compared to pure drug solubility $(0.018 \mathrm{mg} / \mathrm{mL})$. Natural gums, agar, and karaya gum were modified, and the swelling nature and viscosity of treated agar and modified-karaya gum were minor. Formulations with modified gums as carriers showed fast release (treated agar $87.56 \pm 1.40 \%$ release by K10 and modified karaya gum $93.73 \pm$ $1.35 \%$ release by K20) when compared to agar (79.46 $\pm 1.37 \%$ release by K5) and karaya gum $(82.16 \pm 1.37$ $\%$ release by K15). When compared to natural carriers, synthetic carriers PEG $4000(101.83 \pm 1.14 \%$ release in 60 mins by K25) and PEG 6000 (101.19 $\pm 1.12 \%$ release in 30 minutes by K30) showed more significant release. When compared to solid dispersions by physical mixture, kneading method formulations showed fast release. FTIR studies confirmed that there is no interaction between the drug and excipients. The solid-state characterization of solid dispersion formulation by XRD and DSC studies demonstrated that the drug present in the formulation was in an amorphous state. The optimized formulation was subjected to stability studies and was found to be stable. Hence, it can be concluded that solid dispersions of fenofibrate prepared by kneading method with synthetic carrier PEG 6000 are better in enhancing the dissolution rate.

The solubility/dissolution behavior is a crucial factor influencing its oral bioavailability, being the rate-limiting step for absorption of drugs from the gastrointestinal tract. For effective pharmacological action, aqueous solubility is the essential criteria for prompt dissolution and sound absorption. The study by Vimalson et al. (2018) [16] was aimed to enhance the solubility of poorly water-soluble drug (BCS Class II), fenofibrate individually using water-soluble polymers like polyethylene glycol (PEG 6000) (fusion method) and polyvinyl pyrrolidone (PVP K30) (solvent evaporation method) in various ratios like 1:1, 1:2, 1:3 and 1:4 separately. Initially, pre-formulation studies like drug excipient compatibility studies by FTIR, DSC, and determination of saturation solubility of drug individually in various media like distilled water, $0.1 \mathrm{~N}$ hydrochloric acid, and $\mathrm{pH}$ 7.4 phosphate buffer. The formulated solid dispersions were evaluated for percentage yield, drug content, and in vitro dissolution studies. The results of pre-formulation studies revealed that there was no interaction between drug and excipients, and the pure drug was poorly soluble in water. The percentage yield of all formulations was in the range of 60-96\%, and drug content was in the range of 56-82 $\mathrm{mg}$. The solid dispersion containing polyvinyl pyrrolidone $\mathrm{K} 30$ in 1:4 ratio showed the highest drug release at the end of 30 minutes than other formulations. Finally, it was concluded that solid dispersion prepared with PVP K-30 in 1:4 ratio by solvent evaporation method was more soluble than fusion.

Fenofibrate is a lipid-lowering agent used in the treatment of hyperlipidemia. Faruki et al. (2014) [17] has designed and evaluated the solid dispersion technique by solvent evaporation method to improve the solubility and oral absorption of fenofibrate in the gastric fluid to enhance its dissolution rate. Poloxamer 188, Poloxamer 407, Polyethylene glycol (PEG) 6000, Polyvinyl Pyrrolidone (PVP), Hydroxypropyl methylcellulose (HPMC), and Mannitol have been used as the hydrophilic polymers which were employed as carriers for the formulation of solid dispersion with the model drug in the ratio of (Drug: Carriers) 1:1, 1:3, 1:5, 1:7 and 1:10. The pure drug and solid dispersions with all their ratio were characterized using FTIR techniques. The effect of solvent evaporation methods preparing solid dispersion on dissolution behavior was investigated. Dissolution studies indicated a significant increase in the dissolution of fenofibrate when dispersed in carriers. In all the cases, solid dispersions showed improved dissolution of fenofibrate compared to that of pure drugs. It was observed 


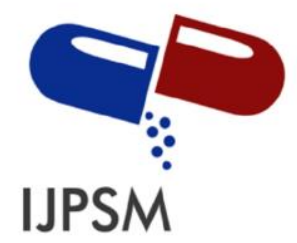

\author{
Nelvia Helsinta et al, Int. Journal of Pharmaceutical Sciences and Medicine (IJPSM), \\ Vol.6 Issue. 6, June- 2021, pg. 42-51
}

ISSN: 2519-9889

Impact Factor: 3.426

that a higher concentration of carriers in preparing solid dispersion showed a higher release of fenofibrate. Solid dispersion prepared with Poloxamer 188 showed the fastest. Full release (93.74 \%) among all formulations and solid dispersions with PVP, HPMC, Poloxamer 407, PEG 6000, Mannitol showed 88.21\%, $88.14 \%, 82.87 \%, 76.50 \%$, and $65.77 \%$ release respectively in 1:10 ratio within 1 hour whereas pure fenofibrate showed only $23.60 \%$ release. The release of drug was plotted in zero-order, first-order, Korsmeyer and Higuchi release pattern. The correlation coefficient values of the trend lines of the graphs showed that the formulations best fit in Higuchian release pattern.

Fenofibrate is a lipid-lowering drug used to treat hyperlipidemia, which is not soluble in water and lower absorption in gastric fluid. To improve the solubility and oral absorption of the drug in gastric juice and enhance its dissolution rate, Patel et al. (2010) [18] have designed and evaluated the solid dispersions and lyophilization of dispersion. Solid dispersions of fenofibrate were prepared using PEG 6000, Poloxamer 407, and a mixture of PEG 6000 and Poloxamer 407 (1:1 mixture). The effect of melt and solvent methods of preparation of solid dispersion on dissolution behavior was also investigated. Dissolution studies indicated a significant increase in dissolution of fenofibrate when dispersed in PEG 6000 and Poloxamer 407. Physical mixtures containing PEG and Poloxamer 407 also showed improved dissolution of fenofibrate compared with that of pure drug, indicating the solubilizing effect of PEG 6000 and Poloxamer 407. Solid dispersions containing fenofibrate/Poloxamer 407, 1: 8 showed a 14-fold increase in dissolution after 60 min (D60) and another dispersion containing fenofibrate/PEG 6000, 1:10, showed an 8-fold rise in the $0.1 \mathrm{~N} \mathrm{HCl} \mathrm{systems.}$ The dispersion containing six parts of the PEG 6000: Poloxamer 407 mixture (PEG 4000/PEG 6000, 1:1 mixture) showed a 12-fold increase in D60 compared with pure drug. When the solvent method prepared multi-carrier solid dispersion containing six parts of variety, the D60 value was about 2-fold that of the same dispersion prepared by the melt method. The dissolution of lyophilized solid dispersions further increased the dissolution of fenofibrate significantly.

Fenofibrate is a lipid-lowering drug used to treat hyperlipidemia, which is not soluble in water and lower absorption in gastric fluid. To improve the solubility and oral absorption of the drug in gastric juice and enhance its dissolution rate, Prasad and Verma (2014) [19] have evaluated the solid dispersions. Solid dispersions of fenofibrate were prepared using PEG 4000, PEG 6000, and a mixture of PEG 4000 and PEG 6000. The effect of solvent methods of preparation of solid dispersion on dissolution behavior was also investigated. Dissolution studies indicated a significant increase in dissolution of fenofibrate when dispersed in PEG 4000 and PEG 6000. Physical mixtures containing PEG 4000 and PEG 6000 also showed improved dissolution of fenofibrate compared with that of pure drug, indicating the solubilizing effect of PEG 4000 and PEG 6000. Solid dispersions containing fenofibrate/PEG 4000, 1: 5, shown an 8-fold increase in dissolution after $60 \mathrm{~min}$ (D60), and another dispersion containing fenofibrate/PEG 6000, 1:5, showed a 14-fold increase in the $0.1 \mathrm{~N} \mathrm{HCl}$ systems. The dispersion containing the fifth parts of the PEG 4000:PEG 6000 mixture (PEG 4000/PEG 6000, 1:5 mixture) showed a 12-fold increase in D60 compared with pure drug. When multi-carrier solid dispersion containing fifth parts of variety was prepared by the solvent method, the D60 value was about 2 -fold that of the same dispersion prepared by the solvent method. The dissolution of the solvent method prepare by solid dispersions further increased the dissolution of fenofibrate significantly.

Fenofibrate is a poorly water-soluble drug having a poor rate of dissolution. Hossen et al. (2014) [20] tried to enhance dissolution of fenofibrate by following solid dispersion of fenofibrate formulations with different dissolution enhancing polymers like HPMC 6 cps, Poloxamer 188, Poloxamer 407, PEG 6000. Total twentyfour formulations were prepared with these polymers in single or combinations. If the solid dispersion is first, other parameters like dissolution, bioavailability will be first. Dissolution of all the formulations was tested for $\%$ drug release profile, mean dissolution time, assay, drug content uniformity, and \% recovery was calculated. From all formulations, F3, F5, F6, F9, F10, F12, and F14 shows the more significant dissolution of Fenofibrate $93.64 \%, 83.66 \%, 100.53 \%, 100.61 \%, 100.95 \%$, and $83.06 \%$, respectively, within 60 minutes of dissolution and decreases the mean dissolution time. Based on in-vitro dissolution results and drug release model kinetics, we can decide that these formulations can increase the dissolution and increase fenofibrate's absorption rate 


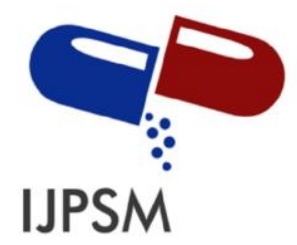

\author{
Nelvia Helsinta et al, Int. Journal of Pharmaceutical Sciences and Medicine (IJPSM), \\ Vol.6 Issue. 6, June- 2021, pg. 42-51
}

ISSN: 2519-9889

Impact Factor: 3.426

and bioavailability. Finally, we can conclude that these formulations enhance the dissolution and bioavailability of fenofibrate and good formulation candidates for fenofibrate in the future.

Polymeric fenofibrate-loaded films and particles aiming at the improved dissolution of this poorly watersoluble drug were prepared by solvent evaporation or co-grinding. Jallouli et al. (2015) [21] have studied HPMC, PVP, and PEG of various molecular weights by these methods. In HPMC, thin films were obtained using the solvent evaporation method, whereas particles were obtained in all other cases. Interestingly, the type of polymer and the preparation method had a substantial impact on system performance. It is not straightforward: For HPMC and PVP, solvent evaporation was much more efficient than co-grinding, whereas the opposite was observed with PEG. Fenofibrate was molecularly dispersed in HPMC and PVP.

In contrast, it was partially dissolved and partially dispersed in the form of tiny crystals in PEG, irrespective of the type of preparation technique. Differences in the particle size could explain why drug release was faster from PVP-based systems prepared by solvent evaporation compared to co-grinding and why the opposite was confirmed in the case of PEG. For HPMC, differences in system homogeneity could explain the effects of the type of preparation method. Significantly, the drug dissolution rate and extent could be substantially increased while assuring stability during at least three months of open storage.

The main objective of the study by Prasanthi et al. (2019) [22] was to compare the effect of natural carriers and synthetic carriers in the dissolution of Fenofibrate (BCS class II), a poorly soluble drug. Fenofibrate is an antihyperlipidemic drug that reduces both cholesterol and triglycerides in the blood. Nowadays, the formulation of poorly soluble compounds for oral delivery is the most frequent and most significant challenge to formulation scientists in the pharmaceutical industry. There are many drugs for which dissolution poses a challenge for formulating oral dosage forms leading to bioavailability problems. By improving the solubility of the drug, solid dispersions were prepared by different methods like physical mixture and kneading method with natural and synthetic carriers like agar, karaya gum, treated agar, modified karaya gum, PEG 4000, and PEG 6000 in the ratios of 1:2 to $1: 10$. Resultant formulations were evaluated for solubility, assay, flow properties, FTIR, X-ray diffraction, DSC, and in vitro dissolution. Solubility of the solid dispersions was enhanced compared to pure drug solubility $(0.018 \mathrm{mg} / \mathrm{mL})$. Natural gums, agar, and karaya gum were modified, and the swelling nature and viscosity of treated agar and modified karaya gum were minor. Formulations with modified gums as carriers showed fast release (treated agar $87.56 \pm 1.40 \%$ release by K10 and modified karaya gum $93.73 \pm 1.35 \%$ release by K20) when compared to agar (79.46 $\pm 1.37 \%$ release by K5) and karaya gum $(82.16 \pm 1.37 \%$ release by K15). When compared to natural carriers, synthetic carriers PEG 4000 $(101.83 \pm 1.14 \%$ release in 60 mins by K25) and PEG $6000(101.19 \pm 1.12 \%$ release in 30 minutes by K30) showed more significant release. When compared to solid dispersions by physical mixture, kneading method formulations showed fast release. FTIR studies confirmed that there is no interaction between the drug and excipients. The solid-state characterization of solid dispersion formulation by XRD and DSC studies demonstrated that the drug present in the formulation was in an amorphous state. The optimized formulation was subjected to stability studies and was found to be stable. Hence, it can be concluded that solid dispersions of fenofibrate prepared by kneading method with synthetic carrier PEG 6000 are better in enhancing the dissolution rate.

\title{
6. Conclusion
}

Several research journals above show that for the fenofibrate solid dispersion system using PEG 6000, fusion (melting), solvent evaporation, dropping, and co-grinding techniques are often used. By using this method, there has been a change in the solubility of medicinal compounds. It was also found that PEG 6000 had a higher dissolution than other formulations and reduced particle size, increasing the solubility and dissolution rate. The greater the speed of melting, the more excellent the solubility of a drug. 


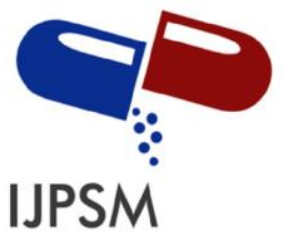

\section{Nelvia Helsinta et al, Int. Journal of Pharmaceutical Sciences and Medicine (IJPSM), Vol.6 Issue. 6, June- 2021, pg. 42-51}

ISSN: 2519-9889

Impact Factor: 3.426

\section{References}

[1]. Jorgensen WL, Duffy EM. Prediction of drug solubility from the structure. Advanced drug delivery reviews. 2002 Mar 31;54(3):355-66.

[2]. Deshmukh AS, Tiwari KJ, Mahajan VR. Solubility enhancement techniques for poorly water-soluble drugs. International Journal of Pharmaceutical Sciences and Nanotechnology. 2017 May 31;10(3):3701-8.

[3]. Gaikwad SS, Mhalaskar RS, Mahale YD, Jain NP. Review on: solubility enhancement of poorly water-soluble drug. Indo Am J Pharm Res. 2014;4:5530-41.

[4]. Ghosh MK, Wahid MA, Ali MA, Barman RK. Formulation and characterization of fenofibrate loaded solid dispersion with enhanced dissolution profile. Pharmacology \& Pharmacy. 2019 Jul 31;10(7):343-55.

[5]. Bonthagarala B, Nama S, Nuthakki S, Kiran KV, Pasumarthi P. Enhancement of dissolution rate of fenofibrate by using various solid dispersion techniques. World Journal of Pharmacy and Pharmaceutical Sciences. 2014 Feb 5;3(3):914-32.

[6]. Zhu W, Romanski FS, Meng X, Mitra S, Tomasson MS. Atomistic simulation study of surfactant and polymer interactions on the surface of a fenofibrate crystal. European journal of pharmaceutical sciences. 2011 Apr 18;42(5):452-61.

[7]. Adkins JC, Faulds D. Micronised fenofibrate. Drugs. 1997 Oct;54(4):615-33.

[8]. Zaini E, Novitasari N, Octavia MD. Pembentukan Sistem Dispersi Padat Amorf Azitromisin Dihidrat dengan Hikroksipropil Metilselulosa (HPMC). Jurnal Sains Farmasi \& Klinis. 2017 May 29;3(2):165-71.

[9]. Chiou WL, Riegelman S. Pharmaceutical applications of solid dispersion systems. Journal of pharmaceutical sciences. 1971 Sep 1;60(9):1281-302.

[10].Singh S, Baghel RS, Yadav L. A review on solid dispersion. International journal of pharmacy \& life sciences. 2011 Sep 1;2(9).

[11]. Bhusnure OG, Kazi PA, Gholve SB, Ansari MM, Kazi SN. Solid dispersion: an evergreen method for solubility enhancement of poorly water-soluble drugs. International journal of research in pharmacy and chemistry. 2014;4(4):906-18.

[12]. Mogal SA, Gurjar PN, Yamgar DS, Kamod AC. Solid dispersion technique for improving the solubility of some poorly soluble drugs. Der Pharmacia Lettre. 2012;4(5):1574-86.

[13].Leuner C, Dressman J. Improving drug solubility for oral delivery using solid dispersions. European Journal of Pharmaceutics and Biopharmaceutics. 2000 Jul 3;50(1):47-60.

[14]. Vinay VN, Venkatesh K, Phanindra K, Keerthi S, Swetha K. Formulations and Evaluations of Solid Dispersions of Fenofibrate for Dissolution Rate Enhancement. Journal of Chemical and Pharmaceutical Research. 2012;4(11):4752-6.

[15].Prasanthi D, Prakash C, Aishwarya KL. Solid dispersions of fenofibrate by dropping method. Int J Pharm Sci Res. 2019;10:4995-5001.

[16]. Vimalson DC, Parimalakrishnan S, Jeganathan NS, Anbazhagan S. Enhancement of solubility and dissolution characteristics of fenofibrate by solid dispersion technique. International research journal of pharmacy, 2018;9(10):145-50.

[17].Faruki MZ, Razzaque E, Rishikesh RA, Bhuiyan MA. Design, formulation development, and solubility enhancement of fenofibrate, a water-insoluble drug by solid dispersion technique. World Journal of Pharmaceutical Research. 2014 Jun 28;3(6):1801-14.

[18].Patel T, Patel LD, Patel T, Makwana S, Patel T. Enhancement of dissolution of fenofibrate by solid dispersion technique. Int. J. Res. Pharm. Sci. 2010;1(2):127-32.

[19].Prasad H, Verma NK. Development and evaluation of solid dispersion of fenofibrate using polyethyleneglycol as a carrier. Der Pharmacia Lettre. 2014;6:63-9.

[20]. Hossein SM, Sarkar R, Towhid MH, Sultan MT, Aziz NA. Study on the effect of different polymers on the invitro dissolution profile of fenofibrate by solid dispersion technique. Journal of Applied Pharmaceutical Science. 2014 Jun 1;4(6):56.

[21].Jallouli Y, Willart JF, Siepmann F, Descamps M, Danede F, Siepmann J. Preparation of polymeric fenofibrate formulations with accelerated drug release: solvent evaporation versus co-grinding. Journal of Drug Delivery Science and Technology. 2015 Dec 1;30:397-407.

[22].Prasanthi D, Jagadish G, Aishwarya KL. Solid dispersions of Fenofibrate: Comparision of natural and synthetic carriers. Pharm Innov J. 2019;8:42-50. 


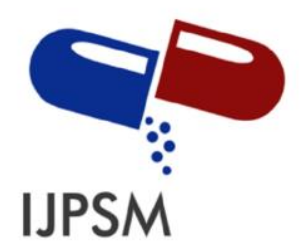

Nelvia Helsinta et al, Int. Journal of Pharmaceutical Sciences and Medicine (IJPSM), Vol.6 Issue. 6, June- 2021, pg. 42-51

ISSN: 2519-9889

Impact Factor: 3.426

[23]. Salman A, Nasrul E, Rivai H, Ben ES, Zaini E. Physicochemical characterization of amorphous solid dispersion of ketoprofen-polyvinylpyrrolidone K-30. Int J Pharm Pharm Sci. 2015;7:209-12.

[24]. Rosaini H, Rivai H, Octavia MD, Rosanti EY, Makmur I. The Effect of Different Concentration of Poloxamer 188 on Nanocrystalline Characteristics of Celery Herb Extract (Apium graveolens L.). Sch Acad J Pharm. 2021 Jan;10(1):1-5.

\section{A Brief Author Biography}

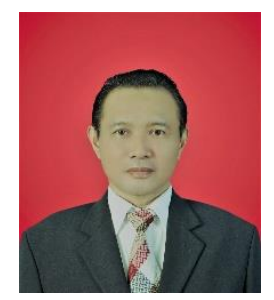

Prof. Dr. Harrizul Rivai, M.S. was born in Payakumbuh, West Sumatra, on 4 September 1953. His father is Rivai Said, and his mother is Saridahanum Syofyan. The author obtained a Bachelor of Pharmacy from the Department of Pharmacy, Faculty of Mathematics and Natural Sciences, Padjajaran University, Bandung (1976), a Master of Science degree from the Bandung Institute of Technology (1984), and a Doctorate from the Department of Chemistry, Faculty of Mathematics and Natural Sciences, Andalas University, Padang (2011). Now the Author is a Professor and Researcher at the Faculty of Pharmacy, Andalas University, Padang. The author also serves as Deputy Chair of Academic Affairs at the YPTIK Padang College of Pharmacy (STIFARM). The author wrote the book "Principles of Chemical Examination" (Publisher UI-Press, 1995), translated the book "Pharmaceutical Statistics" (EGC Medical Book Publishers, 2010), and wrote "Chapter 4" in the book "Recent Research Advances in Biology Vol. 4" (Book Publisher International, India, and United Kingdom, 2020), and wrote the book "Chinese Petai (Leucaena leucocephala): Traditional Uses, Phytochemicals, and Pharmacological Activities" (Deepublish, Yogyakarta, 2021). He wrote "Chapter 9" in the book "Recent Research Advances in Biology Vol. 7" and "Chapters 5, 6, 7, and 8" in the book "Technological Innovation in Pharmaceutical Research Vol. 3 (Book Publisher International, India, and United Kingdom, 2021). The author has also written articles in various international journals in science fields, including chemistry, biology, and pharmacy. 